\title{
Treatment outcome of snake bite patients: A prospective observational study at tertiary care hospital
}

\author{
Shital Rathod ${ }^{1}$, Arvind Chavhan², Deepika Ramrao Dharmkare ${ }^{3 *}$, Koustubh Bavdhankar ${ }^{4}$ \\ $\left\{{ }^{1}\right.$ Associate Professor, ${ }^{3,4}$ JR3 Medicine, Department Of Medicine $\}$ \{ ${ }^{2}$ Associate Professor, Department Of Paediatrics $\}$ \\ Dr. Shankarrao Chavhan Government Medical College, Nanded, INDIA. \\ Email: deepikadharmkare@gmail.com
}

$\underline{\text { Abstract }}$

\begin{abstract}
Background: Snake-bite is one of the most life-threatening bio-weapon system in the nature which may cause local to systemic complication. Aim: To analyse the outcome of AKI after snake-bite. Material and Methods: A total of 200 patients of either gender with age $>12$ years having history of snake bite with signs of envenomation were investigated and treated in a tertiary care hospital. Outcome was analysed. Results: Anti-snake venom was given to all cases in the study. Antibiotics, fresh frozen plasma, whole blood and platelets was given to $48 \%, 19 \%, 9 \%$ and $7.5 \%$ cases respectively. Mortality rate among snake bite cases in present study was reported as $2 \%$. and due to snake bite induced AKI was $19 \%$. Conclusion: Mortality rate among snake bite cases was reported as $2 \%$ and due to snake bite induced AKI was 19\%. Lapse of time in presenting to the hospital is the predictors of poor outcome in snake bite induced acute kidney injury. Early ASV administration and proper supportive management after ASV administration is of utmost importance, for a good patient outcome.
\end{abstract}

Keywords: Snake bite, anti-snake venom, acute kidney injury, mortality

\section{*Address for Correspondence:}

Dr Deepika Ramrao Dharmkare., JR3 Medicine, Department Of Medicine, Dr. Shankarrao Chavhan Medical College, Nanded, INDIA.

Email: deepikadharmkare@gmail.com

Received Date: 29/11/2019 Revised Date: 22/01/2019 Accepted Date: 04/02/2020

DOI: https://doi.org/10.26611/10211524

This work is licensed under a Creative Commons Attribution-NonCommercial 4.0 International License. (oc)) EY-NC

\begin{tabular}{|l|l|}
\hline \multicolumn{2}{|c|}{ Access this article online } \\
\hline Quick Response Code: & Website: \\
\hline & www.medpulse.in \\
\cline { 2 - 2 } & \\
\hline
\end{tabular}

\section{INTRODUCTION}

Snake-bite is one of the most life-threatening bio-weapon system in the nature which may cause local to systemic complication in the form of neurotoxicity or hematotoxicity. It is a common medical emergency and an occupational hazard especially in tropical countries like India. It is a common occupational hazard mainly in farmers, plantation workers, herders and laborers leading to significant morbidity and mortality that remains largely unreported. The true global burden of snake bite is unknown due to lack of standardized and underreporting. Most snake bites and fatalities occur in Asia, south east, and sub-Saharan Africa, with India reporting the highest mortality due to snake bites. ${ }^{1}$ Acute kidney injury (AKI) is an important complication of snake bite and a major cause of mortality. AKI is common after bites from myotoxic or haemotoxic snakes. These snakes are Russell's viper, saw scaled viper, hump nosed pit viper, green pit viper, and sea snake. Hemorrhage, hypotension, disseminated intravascular coagulation (DIC), intravascular hemolysis, and rhabdomyolysis enhance renal ischaemia leading to AKI. ${ }^{2}$ This study was conducted at tertiary care centre in western Maharashtra, which is one of the fast-growing agricultural areas. The present study was conducted to analyse the outcome of AKI after snake-bite. 


\section{MATERIAL AND METHODS}

The present prospective observational study was conducted in the wards of Department of General medicine at a tertiary care hospital in Maharashtra. All the patients with history of snake bite who fulfilled the inclusion and exclusion criteria, getting admitted at the tertiary care hospital.

Sample size

A total of 200 snake bite patients were selected by consecutive type of non-probability sampling method.

\section{Inclusion criteria}

- Patients of either gender with age $>12$ years having history of snake bite with signs of envenomation.

- Progressive elevation of serum creatinine $>0.3$ $\mathrm{mg} / \mathrm{dl}$ from baseline, a percentage increase in the serum creatinine concentration of $>50 \%$ or oliguria of less than $0.5 \mathrm{ml} / \mathrm{kg} / \mathrm{hr}$ for more than 6 hours.

Exclusion Criteria

- The patients with source of bite not identified. SLEp?

- Patients with pre-existing renal disease with history of snake bite. istep?

- Patients discharged against medical advice

- Patients with risk factors for developing renal disease with history of snake is ipepite (diabetes, hypertension, connective tissue diseases and

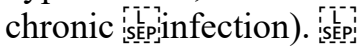

- Exposure to nephrotoxic drugs/toxins.

Methodology

Data was collected using a pretested proforma meeting the objectives of the study. Detailed history, physical examination and necessary investigations were undertaken. The purpose of the study was explained to the patient and informed consent was obtained. Using noninvasive methods acute kidney injury in snake bite patients who fulfil the inclusion criteria is assessed. Acute Kidney Injury (AKI) was defined as an "abrupt (within 48 hours) absolute increase in the serum creatinine concentration of $\geq 0.3 \mathrm{mg} / \mathrm{dl}$ from baseline, a percentage increase in the serum creatinine concentration $\geq 50 \%$ or oliguria of 0.5 $\mathrm{ml} / \mathrm{kg} / \mathrm{hr}>6$ hours. All the patients were managed as per standard hospital protocol and outcome as alive or dead was noted. Laboratory investigations done were Haemoglobin, Total leukocyte count, Platelet count, Whole Blood Clotting Time, Bleeding Time, Blood Urea, Serum Creatinine, Urine Microscopy and Prothrombin Time. USG Abdomen and X-ray Chest were also done whenever necessary.

Statistical Analysis

The quantitative data was represented as their mean $\pm \mathrm{SD}$. Categorical and nominal data was expressed in percentage. The t-test was used for analysing quantitative data, or else non parametric data was analyzed by Mann Whitney test and categorical data was analyzed by using chi-square test. Pearson correlation co-efficient was used for computing correlation between quantitative variables. The significance threshold of $p$-value was set at $<0.05$. All analysis was carried out by using SPSS software version 21.

\section{RESULTS}

Incidence of Acute Kidney injury among snake bite cases in present study was reported as $13.5 \%$. In only 4 cases $(2 \%)$, we were able to identify snake and in all the cases, it was viper snake. Mean age of the study cases was 36.39 years with maximum number of cases i.e. $63 \%$ were in active age group of 21-40 years of age. Male predominance was seen in present study with $53 \%$ cases as compared to $47 \%$ females. Most common occupation among study cases was farming (53\%). Most common urinary complaints were hematuria, oliguria $(16 \%)$ and reduced urinary output $(15.5 \%)$. Hematological conditions reported in present study were raised PT/ INR (15.5\%) and leucocytosis $(11.5 \%)$. Other conditions seen were anemia $(5.5 \%)$ and thrombocytopenia $(6.5 \%)$.

Table 1: Urinary and hematological complaints

\begin{tabular}{ccc}
\hline Complaints & No. of patients & Percentage \\
\hline Urinary complaints & 32 & \\
Hematuria & 32 & $16 \%$ \\
Oliguria & 22 & $16 \%$ \\
Anuria & 31 & $15.5 \%$ \\
Reduced urine output & & \\
Hematological complaints & 11 & $5.5 \%$ \\
Anaemia & 13 & $6.5 \%$ \\
Thrombocytopenia & 1 & $0.5 \%$ \\
Leucopenia & 23 & $11.5 \%$ \\
Leucocytosis & 31 & $15.5 \%$ \\
Raised PT/INR &
\end{tabular}

RBCs in Urine and raised WBCT were seen in $17 \%$ and $18 \%$ cases respectively. Raised blood urea at baseline was reported in $11 \%$ cases which increased to $15.5 \%$ by the end of 24 hours. Mean blood urea was $24.52 \mathrm{mg} \%$ at baseline which 
increases to $28.06 \mathrm{mg} \%, 31.58 \mathrm{mg} \%$ and $34.37 \mathrm{mg} \%$ by the end of 24,48 and 72 hours respectively. Raised serum creatinine at baseline was reported in $14 \%$ cases which increased to $16 \%$ by the end of 48 hours. Mean s. creatinine was $0.99 \mathrm{mg} \%$ at baseline which increases to $1.28 \mathrm{mg} \%, 1.66 \mathrm{mg} \%$ and $2.04 \mathrm{mg} \%$ by the end of 24,48 and 72 hours respectively. Mean urine output was $1533.67 \mathrm{ml}$ at baseline which decreases to $1449 \mathrm{ml}$ by the end of 48 hours. The urine output increases afterward and reached $1608 \mathrm{ml}$ by the end of 72 hours.

Table 2: Laboratory investigations in study subjects

\begin{tabular}{ccc}
\hline Investigations & Mean \pm SD & P value \\
\hline Blood urea & & \\
Baseline & $24.52 \pm 9.94$ & $<0.01$ \\
$24 \mathrm{hrs}$ & $28.06 \pm 15.80$ & Significant \\
$48 \mathrm{hrs}$ & $31.58 \pm 22.42$ & \\
$72 \mathrm{hrs}$ & $34.37 \pm 28.19$ & \\
Br. creatinine & & \\
$24 \mathrm{hrs}$ & $1.28 \pm 1.07$ & Significant \\
$48 \mathrm{hrs}$ & $1.66 \pm 2.01$ & \\
$72 \mathrm{hrs}$ & $2.04 \pm 3.03$ & \\
Baseline & $1533.67 \pm 411.69$ & \\
$24 \mathrm{hrs}$ & $1494.72 \pm 486.53$ & $<0.01$ \\
$48 \mathrm{hrs}$ & $1449.75 \pm 411.69$ & Significant \\
$72 \mathrm{hrs}$ & $1608.44 \pm 387.85$ & \\
\hline
\end{tabular}

A total of $18 \%$ cases reported to hospital within 3 hours after snake bite while 57\% reported within 4 to 6 hours. In 3\% cases delay was more than 12 hours. Before coming to hospital, $3 \%$ cases received anti-snake venom.

Table 3: Distribution of study subjects as per management

\begin{tabular}{ccc}
\hline Management & N & $\%$ \\
\hline ASV & 96 & $48.0 \%$ \\
Antibiotics & 96 & $48.0 \%$ \\
FFP & 38 & $19.0 \%$ \\
Platelets & 15 & $7.5 \%$ \\
Whole Blood & 18 & $9.0 \%$ \\
\hline
\end{tabular}

Anti-snake venom was given to all cases in the study. Antibiotics, fresh frozen plasma, whole blood and platelets was given to $48 \%, 19 \%, 9 \%$ and $7.5 \%$ cases respectively. Mortality rate among snake bite cases in present study was reported as $2 \%$.

\begin{tabular}{|c|c|c|}
\hline Outcome & No. of patients & Percentage \\
\hline Alive & 196 & $98.0 \%$ \\
\hline Death & 4 & $2.0 \%$ \\
\hline Total & 200 & $100.0 \%$ \\
\hline
\end{tabular}

\section{DISCUSSION}

Mortality rate among snake bite cases was reported as $2 \%$ and mortality among cases with AKI was $19 \%$ in the present study. Incidence of Acute Kidney injury among snake bite cases in present study was observed as $13.5 \%$. Asian continent has the highest incidence and in Thailand, Sri Lanka and India, snake bite was complicated by AKI in $5 \%,{ }^{3} 27 \%,{ }^{4}$ and $13-32 \%$, which is in accordance with the findings of the present study. ${ }^{5,6}$ The prevalence of AKI in Menon JC et al. ${ }^{7}$ was $21 \%$, which is slight higher than present study which can attributed to snake species and regional variation. However, results of the present study are comparable to the other reported series in India which are in the range of $13-32 \% .{ }^{8,9}$ Comparable data are available from several other countries as well wherein, the incidence of acute renal failure is $\sim 11 \%, 6.2 \%, 5 \%$ and $27 \%$ in Nigeria, Middle East, Thailand and Ceylon, respectively. ${ }^{10}$ It has been long believed that Russell's viper and the saw scaled viper were the species causing AKI in snakebite. Recently, H. hypnale has also reported to be a common cause of AKI by some authors but present study could not evaluate this association as species was identified in only 4 cases although all of the four cases were vipers and also vipers are very commonly found in region of study. In addition to early detection of clinical signs and symptoms of snakebite, early administration of 
anti-snake venom (ASV) is known to reduce the morbidity and mortality. Anti-snake venom was given to all cases in the study. Antibiotics, fresh frozen plasma, whole blood and platelets was given to $48 \%, 19 \%, 9 \%$ and $7.5 \%$ cases respectively. Indrani D et al.. ${ }^{11}$ ASV was given to $87.88 \%$ of cases. In the study of Mahajan and Mhaskar, ${ }^{12}$ which is in accordance to the present study. $50.66 \%$ patients received ASV; whereas in other two other studies, ${ }^{13,14}$ ASV was given to $90 \%$ and $91.7 \%$ of patients respectively. Harshavardhana $\mathrm{H}$ et $a l .{ }^{4}$ reported that ASV was given to $100 \%$ of the cases. Menon JC et al. ${ }^{7}$ reported $(85 \%)$ of victims needed ASV and others did not require it and antibiotics, fresh frozen plasma and other treatment was given to patients as required, as in present study. Mortality rate among snake bite cases with AKI was $19 \%$ in the present study. Our results are in accordance with Dineshkumar T et al. ${ }^{15}$ the mortality reported in their study is $15.5 \%$ and the risk factors were the presence of coagulopathy and uraemic encephalopathy.

\section{CONCLUSION}

Mortality rate among snake bite cases was reported as $2 \%$ and due to snake bite induced AKI was 19\%. Lapse of time in presenting to the hospital is the predictors of poor outcome in snake bite induced acute kidney injury. AKI is an important complication of snake bite that may lead to mortality. Early ASV administration and proper supportive management after ASV administration is of utmost importance, for a good patient outcome.

\section{REFERENCES}

1. Snake bite, key facts.Available at
http://www.who.int/neglected_diseases/en/. Retrieved on
24/12/19.
Mohapatra B, Warrell DA, Suraweera W, Bhatia P, Dhingra
N, et al.. Snakebite mortality in India: a nationally
representative mortality survey. PLoS Negl Trop
Dis.2011;5:1018.
Kanjanabuch T, Sitprija V. Snakebite nephrotoxicity in Asia.

Semin Nephrol 2008;28: 363-372.

4. Harshavardhana H, Pasha I, Srinivas Prabhu N, Ravi P, Amira N. A study on Clinico-Epidemiological profile of snakebite patients in a tertiary care centre in Bangalore. Global J of Med and Pub Health. 2014;3(2):1-6.

5. Visuvaratnam M, Vinayagamoorthy $\mathrm{C}$, Balakrishnan $\mathrm{S}$. Venomous snake ispepites in North Ceylon - A study of 15 cases. J Trop Med Hyg 1970;73:9-14.

6. Patil TB, Bansod YV. Snake bite-induced acute renal failure: A study of clinical profile and predictors of poor outcome. Ann Trop Med Public Health 2012;5:335-9.

7. Menon JC, Joseph JK, Jose MP, Dhananjaya BL, Oommen OV. Clinical profile and laboratory parameters in 1051 victims of snakebite from a single centre in Kerala, South India. J Assoc Physicians India. 2016 Aug;63:22-9.

8. Kumar V, Sabitha P. Inadequacy of Present Polyspecific Anti Snake venom- A Study from Central Kerala. Indian J Pediatr 2011;78:1225-1228.

9. Lal P, Dutta S, Rotti SB, et al.. Epidemiological Profile of Snakebite cases admitted in JIPMER Hospital. Indian J Community Med 2001;26:36-38.

10. Chippaux JP. Snake-bites: appraisal of the global situation. Bull World Health Organ 1998; 76:515-524.

11. Indrani D, Pragnadyuti M, Rahin M, Srabani G, Balaram G, Rabindranath D. Clinical and Epidemiological Profile of Snake Bite Cases in a Tertiary Care Medical College and Hospital in Eastern India. Saudi Journal of Medical and Pharmaceutical Sciences 2017 May;3(5):408-413.

12. Mahajan S, Mhaskar D. A study of clinical profile of snake bite at a tertiary care centre. International $\mathrm{J}$ of recent scientific research. 2015;6(9):6065-6068. i[s]

13. Joseph JK, Simpson ID, Menon NC, Jose MP, Kulkarni KJ. First authenticated cases of life-threatening envenoming by the hump-nosed pit viper (Hypnalehypnale) in India. Trans R Soc Trop Med Hyg. 2007;101: 85-90.

14. Ghosh S, Maisnam I, Murmu BK, Mitra PK, Roy A, Simpson ID. A locally developed snakebite management protocol significantly reduces overall anti snake venom utilization in West Bengal, India. Wilderness and environmental medicine.

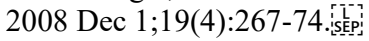

15. Dineshkumar T, Dhanapriya J, Murugananth S, Surendar D, Sakthirajan R, Rajasekar D, Balasubramaniyan T, Gopalakrishnan N. Snake envenomation-induced acute interstitial nephritis. Journal of Integrative Nephrology and Andrology. 2018 Jan 1;5(1):14.

\begin{tabular}{l} 
Source of Support: None Declared \\
Conflict of Interest: None Declared \\
\hline
\end{tabular}

Policy for Articles with Open Access:

Authors who publish with MedPulse International Journal of Medicine, Print ISSN: 2550-7583, Online ISSN: 2636-4751 agree to the following terms: Authors retain copyright and grant the journal right of first publication with the work simultaneously licensed under a Creative Commons Attribution License that allows others to share the work with an acknowledgement of the work's authorship and initial publication in this journal.

Authors are permitted and encouraged to post links to their work online (e.g., in institutional repositories or on their website) prior to and during the submission process, as it can lead to productive exchanges, as well as earlier and greater citation of published work. 